\title{
La educación religiosa en Costa Rica. Aproximaciones teóricas del campo religioso posteriores al voto de la Sala Constitucional
}

\author{
Alexander Cortés Campos*
}

\author{
Recibido: Julio 2012 • Aceptado: Setiembre 2012
}

\begin{abstract}
RESUMEN
Este ensayo busca realizar un debate crítico en torno a la enseñanza de la Educación Religiosa en Costa Rica, teniendo como referente la sentencia de la Sala Constitucional que anuló la Missio Canónica. A partir de este escenario se exploran los antecedentes y las reacciones al voto de la Sala IV. También se analizan algunas aproximaciones teóricas del campo religioso para determinar la situación de la Educación Religiosa posterior al fallo constitucional.
\end{abstract}

Palabras clave: acción de inconstitucionalidad, Missio Canónica, Educación Religiosa, Sala Constitucional, campo religioso, Conferencia Episcopal.

\begin{abstract}
This essay looks for making a critical debate about the teaching of the Religious Education in Costa Rica, having as a reference the judgment of the Constitutional Court which deleted the canonical Missio. From this scenery on, there are explored the background and reactions of the vote of the Forth Court. Furthermore, there are analyzed some theoretical approximations of the religious field to determine the situation of the Religion Education after the constitutional failure.
\end{abstract}

Key words: Unconstitutional action, Canonical Missio, Religion Education, Constitutional Court, religious field, Episcopal Conference.

* Máster en Antropología por la Universidad de Costa Rica, Licenciado en Teología por la Universidad Nacional y egresado del Instituto Teológico de América Central (ITAC), donde realizó estudios de Filosofía y Teología. Ha sido profesor de secundaria y en el nivel universitario. Actualmente es el encargado de la Cátedra de Teología de la Universidad Estatal a Distancia.

E-mail: alexcortez75@hotmail.com 


\section{Introducción}

El voto de la Sala Constitucional o Sala IV, en el 2010, que declara inconstitucional la Missio Canónica (permiso expreso de la Conferencia Episcopal de Costa Rica que necesitaba un docente para impartir lecciones de Educación Religiosa en un centro educativo público) viene a reformar la Educación Religiosa en Costa Rica. De ahí en adelante, el Ministerio de Educación Pública (MEP) será la institución encargada de la formación religiosa en I, II y III ciclos, así como en Educación Diversificada. La Iglesia Católica, que había sido la institución autorizada para guiar los destinos de la Educación Religiosa durante muchos años, pierde su protagonismo y los cimientos de su estructura institucional y doctrinal en dicha materia son fuertemente minados por la sentencia constitucional.

Lo antes dicho provoca crisis y cambios en el campo religioso, como nos referimos en este estudio. Precisamente, la situación recién evocada suscita problemáticas que urge responder, de innegable importancia práctica, que justifican realizar este ensayo. Por eso, nos formulamos la siguiente pregunta: ¿Cómo se encuentra la educación religiosa en Costa Rica, posterior al voto de la Sala Constitucional, desde una perspectiva del campo religioso? Las interrogantes que surgen de tal cuestionamiento las trataremos de contestar en el transcurso de este estudio.

El tema en discusión no gira directamente en torno a si se debe ofrecer Educación Religiosa en escuelas y colegios o no, sino sobre quién debe dirigir y quiénes deben impartir esta asignatura en los centros educativos públicos del país. En efecto, la Iglesia Católica y sectores no vinculados a ella afirman la importancia y actualidad de esta materia. No ven necesario eliminarla del currículo escolar, sino más bien de reformarla adaptándola a las necesidades de la realidad costarricense. Pero no hay consenso y más bien fuertes disputas en torno a quién le corresponde guiar los destinos de esta asignatura y quiénes son los indicados para docentes de Educación Religiosa.

Este estudio se dividió en tres apartados interrelacionados entre sí. En un primer momento, se narran los antecedentes históricos que provocaron el fallo de la Sala IV. En un segundo apartado, se describen las situaciones posteriores que surgieron en el campo religioso a raíz de la sentencia constitucional. Finalmente, se analiza el campo religioso en donde se determina su condición de la realidad en la sociedad costarricense.

Se espera que este estudio explique un conjunto de aspectos 
interrelacionados que se dan en el campo religioso. Sus resultados pueden ser necesarios para realizar -en un futuro cercano- un diagnóstico de mayor profundidad, en el cual se señalen aciertos, deficiencias y oportunidades, para dotar a las autoridades correspondientes del Estado, de las distintas iglesias radicadas en el país y de diversos sectores de mejores elementos de juicio para tomar las decisiones adecuadas.

\section{Antecedentes históricos}

El 2 de febrero de 2010, la Sala Constitucional de la Corte Suprema de Justicia, mediante voto 2023-2010, según expediente 08010483-0007-CO, declara inconstitucional el artículo 34, párrafo segundo, del Reglamento a la Ley de Carrera Docente y otras disposiciones relacionadas, debido a la acción de inconstitucionalidad interpuesta por estudiantes, graduados y profesores de las carreras de Enseñanza de la Religión y Teología, de la Universidad Nacional y de la Universidad Estatal a Distancia (Sala Constitucional, 2011).

Este fallo constitucional deja sin efecto la Missio Canónica y designa al Departamento de Carrera Docente del Servicio Civil en coordinación con la Dirección de Recursos Humanos del MEP, como las únicas instancias autorizadas a reclutar docentes de Educación Religiosa; así mismo son las únicas que tienen potestad de nombrar profesores y maestros en esta asignatura de manera interina y en propiedad, de la misma forma como son nombrados los docentes de otras materias. También, entre otros enunciados, solicita al MEP adecuar los programas de Educación Religiosa de forma ecléctica para que se ajusten a los diversos credos religiosos existentes en el país. A partir de estas premisas, podemos recrear los antecedentes de este caso, tomando como referencia los datos que se encuentran en el fallo integral de la Sala IV, que a continuación se detallan:

En setiembre de 1975, se emitió el Decreto Ejecutivo 5288-P, que modificó el artículo 34 del Reglamento del Estatuto de Servicio Civil, en donde se establecía que, para la selección del personal dedicado a la Educación Religiosa en los centros educativos públicos, los interesados debían contar con el visto bueno otorgado previamente por la Conferencia Episcopal de la Iglesia Católica. Como consecuencia, nadie podía concursar si no había recibido la Missio Canónica, aunque contara con los requisitos mínimos. Si una persona sin la licencia mencionada se postulaba, el Departamento de Educación Religiosa del MEP la excluía en forma automática de la lista de 
candidatos postulados para la Dirección de Servicio Civil. Si el reclutamiento se hacía directamente en el Servicio Civil, esta instancia era la encargada de excluirla por no contar con dicha licencia. De una $\mathrm{u}$ otra forma, las personas que no tuvieran la Missio Canónica, aunque sobrepasaran los requisitos mínimos solicitados, no podían ejercer la docencia en Educación Religiosa en ningún centro educativo del país. Además, la mayoría de las veces, el asesor nacional era un sacerdote y los asesores regionales también. Si se asignaba a un laico como asesor regional, regularmente seguía las mismas políticas de exclusión hacia las personas que no contaran con la licencia mencionada, por lo cual se hacía difícil ejercer la docencia en esta asignatura sin contar con el beneplácito de la Conferencia Episcopal.

Para Hess (2010), la Missio Canónica solo era otorgada a personas que reunieran una serie de requisitos eclesiales, como los siguientes: ser practicante católico, con una conducta moral intachable, tener un compromiso pastoral comprobado, recomendaciones de personas ligadas a la Iglesia Católica y casados por esta en caso de serlo; por consiguiente, no se permitía a nadie casado de forma civil y mucho menos en unión libre. Los estudios académicos universitarios en el área quedaban en segundo plano, debido a que los requisitos previamente descritos estaban por encima de ellos. No es de extrañar que muchos maestros y profesores de Educación Religiosa fueran catequistas y $\sin$ estudios universitarios en esta área. Como la Iglesia Católica tenía la potestad de designar a los docentes en Educación Religiosa, el criterio técnico del MEP no contaba para nada. Los requisitos morales descritos propiciaban una evidente desigualdad, en relación con los docentes de otras asignaturas académicas pues, según la normativa del Servicio Civil, únicamente se requiere demostrar idoneidad académica y profesional.

La Conferencia Episcopal de Costa Rica (1990) formuló, en el artículo 90 de la sesión 10-90, del mes de setiembre de 1990, una serie de lineamientos relacionados con la enseñanza de la Educación Religiosa en centros educativos públicos, pudiéndose resumir lo siguiente:

a. En los centros públicos como privados la Iglesia Católica "es la única que tiene la misión y la responsabilidad de dar la formación a los Maestros y Profesores de Educación Religiosa Escolar".

b. Se desautoriza de forma expresa a "cualquier curso de capacitación y formación de cualquier universidad o 
institución tendiente al ejercicio docente de Maestros y Profesores de Educación Religiosa Escolar".

c. Los obispos católicos manifiestan "Conceder la Missio Canónica solamente a quienes hayan concluido el proceso de formación en la Escuela Normal Superior, Instituto Pedagógico de Religión".

De lo anterior, se puede inferir que la Iglesia Católica se atribuyó el derecho exclusivo -y por supuesto excluyente- de determinar cuáles personas podían formarse académicamente para impartir la docencia en Educación Religiosa y cuáles instituciones públicas y hasta privadas podrían hacerlo y cuáles no. Debido a esta directriz, solo los egresados y graduados de la Universidad Católica Anselmo Llorente y Lafuente y otras personas que no tenían estudios universitarios en Educación Religiosa, pero que gozaban del visto bueno de los obispos costarricenses, podían impartir clases de esta asignatura. Por un lado, esto produjo un verdadero monopolio a favor de esta universidad privada $y$, por otro lado, la instauración de una dictadura en el campo de la Educación Religiosa por parte de la Conferencia Episcopal de Costa Rica.

Debido a las circunstancias apuntadas, la Iglesia Católica impuso su poder dictatorial en todo el territorio nacional, por lo cual si un docente de esta asignatura se encontraba de forma "inmoral" o no se apegaba a los lineamientos eclesiales era separado de su cargo, pues era difícil permanecer oculto sin ser descubierto ante el sistema de fiscalización interpuesto por la Iglesia Católica Romana. Para Hess (2010), la Iglesia se reservó el derecho de revocar o retirar la Missio Canónica a cualquier persona, sin importar que la hubiera obtenido previamente. Solo se necesitaba cualquier causa que -a criterio de los obispos- justificara la pérdida de esta licencia. Por su parte, para los demandantes, según el voto de la Sala Constitucional (2011), a los docentes que se divorciaban o se cambiaban de credo religioso, por ejemplo, inmediatamente se les revocaba la Missio Canónica y se los excluía del nombramiento para labores de Educación Religiosa, lo cual equivalía a un despido solapado, puesto que el MEP se encontraba vinculado o asociado a las decisiones de la Iglesia Católica, burlando así los procedimientos y garantías de defensa propios del régimen de Servicio Civil.

Todo lo denunciado en la acción de inconstitucionalidad no era nuevo. Desde tiempo atrás, diversas personas y grupos sociales venían alzando la voz sin ningún resultado. Inclusive antes de este voto de 
la Sala IV, se interpusieron recursos de amparo sin obtener conclusiones positivas. El Comité de Derechos Humanos de la Organización de las Naciones Unidas (1994) ya se había pronunciado sobre el tema, constatando las violaciones a los derechos humanos que se estaban realizando y señaló prevenciones severas al país. Este Comité le indicó al Estado costarricense las siguientes observaciones:

- 'Inquieta al Comité la preminente posición otorgada a la Iglesia Católica Romana. El Comité también observa con inquietud el hecho de que ciertas disposiciones de la legislación de Costa Rica (entre otras la Ley de Carrera Docente) confieren a la Conferencia Episcopal Nacional la facultad de impedir efectivamente la enseñanza de religiones distintas del catolicismo en las escuelas públicas y de prohibir que personas no católicas enseñen religión en esas escuelas." (Punto 9)

- $\quad$ "El Comité recomienda que el Estado adopte medidas para asegurar que no haya discriminación en el ejercicio del derecho a la educación religiosa, particularmente con respecto al acceso a enseñanzas religiosas distintas del catolicismo. Las prácticas actuales que someten la selección de instructores religiosos a la autorización de la Conferencia Episcopal Nacional no están en conformidad con el Pacto Internacional de Derechos Civiles y Políticos." (Punto 13)

Estas observaciones señaladas se sumaron a otras que ya se venían planteando de parte de diferentes actores sociales físicos y jurídicos desde la década de los noventas, que solicitaban con insistencia un cambio por parte del Estado en materia religiosa. Posiblemente, el fallo de la Sala IV en el 2010 no se había podido dar años antes, debido a la presión y dominio ejercido por la Iglesia Católica sobre esta Sala Constitucional y de funcionarios judiciales que estaban casados con las políticas eclesiales. No obstante, la renovación parcial de magistrados de la Sala IV, una acción de inconstitucionalidad con una argumentación y depuración jurídica mejores en comparación con los recursos de amparo interpuestos anteriormente sin resultados positivos, cambios en la sociedad costarricense y otros factores externos e internos lograron su objetivo final.

Los diversos demandantes señalaron claramente, en la acción de inconstitucionalidad interpuesta, que había sido violentada una serie de principios constitucionales al no permitírseles impartir la docencia 
en Educación Religiosa, a pesar de contar con los requisitos académicos y de idoneidad solicitados por el MEP al igual que en otras materias. De acuerdo con el criterio de los demandantes, los diferentes principios infringidos fueron los siguientes:

- "Los principios de igualdad y dignidad.

- La libertad de enseñanza.

- La libertad religiosa.

- La libertad de cátedra y las atribuciones constitucionales de las instituciones de educación superior universitaria.

- El derecho al trabajo.

- El principio de reserva legal en materia de regulación de derechos fundamentales.

- Los parámetros constitucionales de razonabilidad $\mathrm{y}$ proporcionalidad.

- Diversas normas propias del derecho internacional de los derechos humanos: la Declaración Universal de los Derechos Humanos, la Convención Americana sobre Derechos Humanos, la Declaración de los Derechos y Deberes del Hombre, el Pacto Internacional de los Derechos Civiles y Políticos y el Convenio de la Organización Internacional del Trabajo (OIT) relativo a discriminación en materia de empleo.
La Sala dio curso a la acción, confiriéndole audiencia a la Procuraduría General de la República, al Ministerio de Educación Pública y a la Conferencia Episcopal de Costa Rica. La primera se manifestó a favor de la acción, mientras que los últimos lo hicieron en contra. Posteriormente se apersonaron también en el expediente, como coadyuvantes, el Instituto Tecnológico de Costa Rica, la Universidad Nacional y la Federación de Estudiantes de la Universidad Nacional (a favor de la acción); así como la Asociación de Profesores de Educación Religiosa (en contra)." (Hess, 2010: párr. 9 y 10$)$.

Todos estos principios violentados, según los demandantes, se generaban a raíz de la negativa de la Conferencia Episcopal de Costa Rica que les impedía ejercer la docencia en Educación Religiosa. Este impedimento ocasionaba injusticia y al mismo tiempo un mal testimonio de parte de la Iglesia Católica, pues se oponía a los principios cristianos emanados de los Evangelios. Finalmente, el 2 de febrero de 2010, la Sala Constitucional (2011: 39) dictaminó la sentencia 2010-02023 y, en el por tanto, señaló lo siguiente: 
"Se declara con lugar la acción y en consecuencia se anula el Art. 34 párrafo segundo del Reglamento a la Ley de la Carrera Docente (Decreto ejecutivo número 2235-E-P del 14 de febrero de 1972) que dice lo siguiente: 'Para la selección del personal dedicado a la educación religiosa, será requisito indispensable la autorización previa que extenderá la Conferencia Episcopal nacional. Sin embargo, la elaboración de las bases y promedios ponderados para la selección previa, tanto del personal propiamente docente como del personal técnico y administrativo docente, estará a cargo de Jurados Asesores de la Dirección General'; en lo demás se declara sin lugar. El Magistrado Mora pone nota. Los Magistrados Cruz, Armijo y Castillo salvan el voto y declaran sin lugar la acción. Los Magistrados Cruz y Castillo ponen nota. -Ana Virginia Calzada M., Presidenta. - Luis Paulino Mora M. -Gilbert Armijo S. -Ernesto Jinesta L. -Fernando Cruz C. -Fernando Castillo V. -Roxana Salazar C."

Esta sentencia de la Sala Constitucional crea un antes y un después en el campo de la Educación Religiosa en Costa Rica. En adelante, el Departamento de Carrera Docente del Servicio Civil en coordinación con la Dirección de Recursos Humanos del MEP serán los encargados de nombrar a los profesores y maestros de forma interina y en propiedad en Educación Religiosa al igual que se hace en otras materias. El único requisito para ejercer la docencia es demostrar idoneidad académica y profesional. De esta forma la Missio Canónica queda enterrada y pasa a ser parte de la historia de la realidad costarricense.

\section{Situaciones posteriores a la sentencia constitucional}

Una vez que se da a conocer la sentencia de la Sala IV, comienzan a salir, en los diferentes periódicos de circulación impresa y medios electrónicos del país en particular, múltiples noticias provenientes de diversos sectores. Por un lado, los que estaban a favor de la apertura de la Educación Religiosa expresaban alegría y temor al mismo tiempo: alegría, porque se había ganado una batalla injusta y al mismo tiempo les abría las puertas al mercado laboral; temor, porque no sabían cuál iba a ser la reacción de la Iglesia Católica ante la derrota. Por otro lado, estaban los que se habían opuesto a la acción de inconstitucionalidad, quienes expresaban su descontento y al mismo 
tiempo la incertidumbre que estaba generando el fallo.

Un mes después de darse a conocer la sentencia de la Sala Constitucional, la Conferencia Episcopal de Costa Rica (2010), compuesta por los diferentes obispos católicos del país, da a conocer una exhortación donde expresa sus preocupaciones, esperanzas y orientaciones, con motivo de la resolución de la Sala Constitucional que anuló la facultad - concedida a los obispos por el Reglamento de la Ley de Carrera Docente- de discernir sobre la idoneidad para el otorgamiento de la Missio Canónica a los docentes de Educación Religiosa como agentes de pastoral, para la enseñanza de esta asignatura en los centros educativos públicos, según se contempla en los planes de estudios del sistema educativo costarricense. Los obispos expresan que respetan la decisión tomada por la Sala IV, pero a la vez les preocupa profundamente la inseguridad y confusión que ha causado esta sentencia en educadores y estudiantes de Educación Religiosa, padres y madres de familia. Al mismo tiempo, los prelados sintetizan sus preocupaciones y orientaciones en los siguientes tres aspectos:

1. La educación religiosa escolar en Costa Rica: Los obispos expresan que una de las finalidades de la educación escolar es hacer que los alumnos valoren y asuman en forma consciente, crítica y creativa su propia cultura. Por su parte, la asignatura de Educación Religiosa se ocupa de la comprensión del mundo cultural desde la visión cristiana, sin la cual el patrimonio cultural y la identidad costarricense se verían seriamente empobrecidos. Agregan que el fundamento de la Educación Religiosa se encuentra en el derecho inalienable que tienen los padres de familia católicos, de educar a sus hijos según su fe y convicciones. Es un derecho humano que debe respetarse, y es deber del Estado costarricense hacer el mayor esfuerzo para que los padres encuentren esta educación en los centros docentes públicos. Además, los obispos citan el artículo 26 de la Declaración Universal de los Derechos Humanos de las Naciones Unidas y el artículo 18.4 del Pacto Internacional de Derechos Civiles y Políticos, para manifestar que la Educación Religiosa -en el ámbito educativo- es un servicio subsidiario del Estado costarricense a la familia, que brinda formación integral a los estudiantes para que desarrollen armónicamente sus propios dotes físicos, morales, intelectuales y espirituales. Se deduce que la Educación Religiosa no es solo una fuente de empleo o relación de carácter laboral. También, los ordinarios externan su preocupación por la tendencia de 
querer remplazar la educación religiosa católica por una enseñanza del hecho religioso de naturaleza multiconfesional o por una enseñanza ética, estética y de valores, negando el derecho de los padres y madres de familia a optar por la educación religiosa católica para sus hijos e hijas.

2. Llamado a los responsables: Los obispos exhortan a las familias católicas, conforme a la exigencia de su condición de bautizados, para que aprovechen el espacio que les otorga nuestro sistema educativo, como aporte insustituible en la formación humana y cristiana de sus hijas e hijos, y que se mantengan alertas para vigilar y defender el derecho inalienable de darles la Educación Religiosa escolar católica. Los prelados hacen un llamado para que el MEP y la Conferencia Episcopal de Costa Rica consoliden el marco jurídico y funcional que ampara actualmente al Departamento de Educación Religiosa, como entidad que vincula al MEP y la Conferencia Episcopal de Costa Rica en esta tarea. Asimismo, abogan por el derecho que asiste a los docentes de Educación Religiosa de participar en dicho ejercicio en todos los ciclos y modalidades del sistema educativo costarricense. Los obispos manifiestan que los docentes de Educación Religiosa, y quienes aspiran a esta carrera profesional, asuman su profesión como una verdadera vocación al servicio de la formación integral de niños, jóvenes y adultos. Asimismo, solicitan respetar la legislación vigente que ampara la Educación Religiosa confesional católica, al tiempo que se consoliden los vínculos de coordinación y complementariedad entre el Estado Costarricense y la Iglesia Católica en el ámbito educativo. Igualmente, el derecho que tienen las familias católicas a educar a sus hijos e hijas de acuerdo con su fe y sus convicciones. Además, reconocen que la Educación Religiosa es una responsabilidad compartida entre la familia, la Iglesia, el Estado y los centros educativos, por lo cual se debe renovar el compromiso eclesial de asumir la Educación Religiosa en los centros docentes y el servicio de las educadoras y los educadores como acción prioritaria enmarcada en la Pastoral Educativa.

3. Conclusión: Los obispos finalizan este comunicado manifestando que se está muy cerca de celebrar setenta años del establecimiento de la Educación Religiosa escolar en Costa Rica, y a ellos les sostiene la certeza de que (citando a Benedicto XVI, en su discurso a los educadores católicos el 17 de abril de 2008): 
"los nobles fines [...] de la educación, fundados en la unidad de la verdad y en el servicio a la persona y a la comunidad son un poderoso instrumento especial de la esperan$z a$. (...) aprovechar los dones del pasado a fin de comprender mejor el presente y proyectarse conscientemente hacia el futuro." (CECOR, 2010: 73)

Prácticamente, este es el más importante comunicado de parte de la más alta jerarquía católica del país que se ha dado a conocer después de la sentencia constitucional. Ha habido otros artículos de opinión que han salido a luz pública de parte de obispos, sacerdotes, profesores de Educación Religiosa, agentes de pastoral y padres de familia, para externar su preocupación y la incertidumbre por la que atraviesa la Educación Religiosa en Costa Rica. En general, todas estas preocupaciones están en concordancia con las ya expuestas por la Conferencia Episcopal costarricense. Por supuesto, también se han dado a conocer artículos de opinión y comentarios de personas que están a favor de la acción de inconstitucionalidad que generó la sentencia constitucional.

Las preocupaciones e incertidumbre se fundamentan en el fallo mismo, puesto que este establece un nuevo escenario para la asignatura de Educación Religiosa en los próximos años. Se incluye el rediseño de los planes de estudio, se ordena la educación ecléctica, la salida definitiva del Departamento de Educación Religiosa del Edificio de la Conferencia Episcopal de Costa Rica - cuyo traslado físico se concretó en el 2011, estableciéndose en el Edificio Raventós (San José)-, la incorporación de docentes no católicos o de otros credos religiosos e incluso de no creyentes para impartir lecciones de Educación Religiosa, la selección de los candidatos a impartir Educación Religiosa en los centros educativos públicos únicamente por parte del Departamento de Carrera Docente del Servicio Civil y la Dirección de Recursos Humanos del MEP y la eliminación de la Missio Canónica. Todas estas medidas fueron establecidas por la Sala IV, lo cual es visto por algunos sectores eclesiales como una extralimitación por parte de esta Sala debido a que, según ellos, la acción de inconstitucionalidad que motivó la sentencia sólo se refería a la Missio Canónica.

Debido a la complejidad del voto, comienzan a surgir diversas interpretaciones de la sentencia. Diferentes sectores gremiales, sociales, políticos, eclesiales y académicos dan su interpretación, generando en algunos casos afirmaciones contrarias. Cada sector lo interpreta de acuerdo con sus intereses, alejándose muchas veces de los verdaderos beneficios que 
necesita la sociedad costarricense. Ante este caos interpretativo, lo más conveniente es que la Sala IV explique el trasfondo del voto para que se desestimen especulaciones e interpretaciones erróneas.

Este escenario de preocupación e incertidumbre se va a ampliar aún más en el 2011, cuando la Dirección de Recursos Humanos del MEP desacredita al Departamento de Educación Religiosa para el reclutamiento de docentes que impartan lecciones de Educación Religiosa. Esto provocó malestar de grupos eclesiales que expresaban su disconformidad con la medida tomada por parte del MEP. Antes de la sentencia constitucional, era normal que el Departamento de Educación Religiosa, con la bendición de la Conferencia Episcopal de Costa Rica y el beneplácito del MEP, reclutara a docentes para impartir Educación Religiosa, debido a que era la instancia encargada de hacerlo. Pero, con el fallo de la Sala IV, esta responsabilidad se le transfirió al Departamento de Carrera Docente del Servicio Civil en coordinación con la Dirección de Recursos Humanos del MEP.

El Jefe del Departamento de Educación Religiosa del MEP, el Lic. José Marvin Salazar Porras (Comunicación personal, 26 de setiembre, 2011, párr. 3), actuando de forma ingenua, premeditada o simplemente por oficio -como se hacía antes del fallo constitucional-, hizo un llamado nacional a los docentes de Educación Religiosa a reclutarse del 3 al 7 de octubre de 2011.

El comunicado solicitaba que todos los interesados debían presentar los siguientes requisitos:

- "Copia de la cédula de identidad.

- Hoja de delincuencia.

- Hoja cliente.

- Título de Bachiller de conclusión de la Educación Diversificada.

- Títulos en Educación Religiosa (si los tiene), otros títulos y certificación o comprobante de universidad si están estudiando Educación Religiosa.

- Carta de recomendación de la autoridad religiosa competente.

- Constancia sacramental (para católicos).

- Constancia de actividad pastoral firmada por la autoridad religiosa competente (otras denominaciones).

- Constancia de categoría profesional (si tiene).

- Constancia de años de servicio.

- Carta de su desempeño docente firmada por las o los directores de las instituciones donde ha laborado en el presente año (en caso de haber laborado).

- Completar el formulario de reclutamiento y firmarlo. 
- Realizar entrevista a cada candidato posterior al reclutamiento y firmar acta donde quede constancia de que se presentó a la entrevista.

- Firmar el acta de reclutamiento abierta por el asesor para este año."

Sin embargo, el M.Sc. Juan Antonio Gómez Espinoza, Director de Recursos Humanos del MEP (Comunicación personal, 30 de setiembre, 2011) envía un comunicado a los directores regionales, donde desaprueba el reclutamiento convocado por el Departamento de Educación Religiosa, refiriéndose de la siguiente forma:

"De manera inconsulta, el Departamento de Educación Religiosa de este ministerio envió, con fecha 26 de setiembre último, un 'aviso urgente' a docentes en propiedad $e$ interinos de esa especialidad, informándoles de un supuesto reclutamiento para interinos, tanto para instituciones públicas como subvencionadas, durante el periodo comprendido entre el 3 y 7 de octubre próximo.

Sobre el particular me permito advertirles, que tal reclutamiento no posee sustento legal alguno, y es violatorio en todos sus extremos de la sentencia emitida por la Sala Constitucional el 2 de febrero de 2010, que mediante Voto No. 2023, anuló el artículo 34 del Reglamento a la Ley de Carrera Docente y dejó sin efecto la denominada Missio Canónica.

En consecuencia, les instruyo en el sentido de desautorizar y dejar sin efecto toda gestión que sobre el tema en referencia se pudiese registrar en el ámbito de su jurisdicción durante el período dicho, toda vez que las únicas instancias legalmente autorizadas para realizar reclutamientos lo son este Despacho en conjunto con la Dirección General de Servicio Civil."

De los dos comunicados anteriores, se puede inferir que el Departamento de Educación Religiosa perdió el protagonismo del cual gozaba antes de la sentencia. El poder que deja vacante dicho Departamento lo asume el MEP con mucho rigor, pues una orden constitucional lo faculta. El MEP se convierte en el rector de la Educación Religiosa en los centros públicos del país, mientras que el Departamento de Educación Religiosa pasa a ser una instancia subordinada de este Ministerio, similar a la de otros departamentos educativos. Por su parte, la Iglesia Católica pierde por completo toda injerencia y potestad que tenía para nombrar a los docentes de esta asignatura. Todo este panorama con diferentes escenarios, descritos en este apartado, merece un análisis de mayor profundidad que desarrollamos a continuación. 


\section{Análisis del campo religioso}

Antes de realizar cualquier análisis del campo religioso, es necesario explicar esta categoría. Para Bourdieu (1997), existe una dicotomía compuesta por instancias objetivamente asignadas que garantizan la producción, reproducción, conservación y difusión de los bienes religiosos, las cuales son el autoconsumo religioso y la monopolización de la producción religiosa por parte de un grupo de especialistas. Estos dos aspectos distribuyen el capital religioso compuesto por bienes de salvación que tienen tipos distintos de sistemas simbólicos. Por lo tanto, existe en la sociedad una especialización y división del trabajo religioso, donde la producción para el autoconsumo religioso cede el paso a la especialización del trabajo específicamente religioso.

Solera y Robles (2001) manifiestan que el campo religioso obedece a un proceso histórico-social concreto en el cual el trabajo de producción religiosa procede de una labor especializada que realiza un determinado sector de la colectividad, compuesto por un cuerpo de especialistas o funcionarios religiosos quienes pasan a ejercer un monopolio sobre la producción y gestión de los bienes de salvación. Este trabajo es reconocido socialmente y se legitima en el contexto de la sociedad en el que se da tal reconocimiento. Como consecuencia, un amplio sector de la colectividad es excluido de las competencias inherentes a la producción religiosa y, en cuanto tal, resultan desposeídos del capital religioso. Por lo general, los especialistas o funcionarios religiosos marginan al laico de la producción y gestión de los bienes de salvación, pero el laico reconoce la legitimidad de su desposeimiento por el hecho mismo de su desconocimiento.

Para Bourdieu (2008), el campo religioso es una estructura diferenciada y compleja que contiene individuos, grupos e instituciones que se encargan específicamente de la producción, reproducción y difusión de los bienes religiosos, necesarios para la satisfacción del interés religioso. Las diferencias de esta estructura procesan las demandas religiosas que se amparan en el mismo campo religioso, pero los factores que interpusieron estas demandas no se limitan únicamente al campo religioso, sino que tienen conexiones complejas y diversas con el contexto o campo económico, político y sociocultural.

Esta estructura de la división de los bienes simbólicos está por encima de la estructura de distribución de los instrumentos de la producción religiosa. Debido a esta circunstancia la colectividad, compuesta por personas concretas, 
resulta atravesada por las diferentes posiciones que los grupos e individuos ocupan en tales estructuras. De este modo, los sistemas simbólicos están yuxtapuestos y predispuestos por su misma estructura a ejercer simultáneamente funciones de inclusión y exclusión, de asociación y de disociación, de integración y de distinción, así como de conocimiento y desconocimiento.

El campo religioso es manipulado por el grupo de especialistas que tiene el poder. Por lo general, en nombre de Dios expresan las indicaciones que debe seguir la colectividad y esta, al mismo tiempo, las obedece como algo normal. Pero cuando la colectividad o parte de ella desaprueba las indicaciones del grupo de especialistas, son rápidamente marginados de los bienes de salvación. Esta exclusión del campo religioso puede llegar a tener repercusiones, también de exclusión, en otros campos como el político y social, convirtiéndose en un fenómeno complejo de mayor envergadura del que aparenta ser.

No obstante, como todo campo religioso se encuentra inmerso dentro de una realidad concreta y es parte de un proceso histórico social, puede ser vulnerable a cambios bruscos. Estos cambios provienen regularmente de grupos o individuos que son parte de la colectividad, que están a favor de la renovación del campo religioso.
Como primera medida, los especialistas del campo religioso desaprueban los cambios propuestos por los grupos o individuos y manipulan al resto de la colectividad para que se opongan. Si los especialistas no pueden revertir los cambios, el campo religioso entra en crisis y el sistema simbólico que lo justifica debe reorientarse. La crisis se expresa en preocupación, incertidumbre o hasta en violencia física.

No es de extrañar que una de las preocupaciones de la Conferencia Episcopal de Costa Rica es motivada por la resolución de la Sala IV que eliminó la Missio Canónica. Los obispos se sienten preocupados, porque parte del campo educativo al que ellos tenían acceso les fue arrebatado. De esta forma, la interrelación que había existido entre el campo religioso y educativo se rompe y los obispos dejan de tener el dominio absoluto sobre los bienes de salvación referidos a la educación religiosa.

Una de las características del campo religioso es que el poder no se comparte de forma masiva, sino que se encuentra restringido en manos de un grupo de especialistas. Cuando son despojados de una parte del poder, tienden a justificar esta pérdida con la preocupación e incertidumbre. Al crear confusión en la colectividad deslegitiman al grupo de laicos que les quitó parte de su poder. Una de las primeras 
reacciones de los prelados costarricenses fue expresar que existía inseguridad y confusión con la sentencia por parte de los educadores y estudiantes de Educación Religiosa, padres y madres de familia. En otras palabras, quieren transmitir a la colectividad que un grupo de personas les está quitando los bienes de salvación y que debido a este grupo pueden quedar sin símbolos de referencia que le den sentido a su vida personal y comunitaria. Los obispos manipulan de esta forma a la colectividad, porque quieren hacer notar que hay caos y no hay un camino claro para seguir, pues ellos como pastores o especialistas del campo religioso son los únicos autorizados de guiar verdaderamente a la colectividad.

El campo religioso está mediado por interés de los especialistas, en nuestro caso la Conferencia Episcopal, los cuales quieren obtener beneficios de los medios de producción de la fe y del mundo simbólico que les rodea. El campo educativo en donde se encuentra la Educación Religiosa -y que está muy ligado al campo religioso- se construye alrededor del interés y tiene por principio "la necesidad de legitimación de las propiedades materiales y simbólicas adjudicadas a un tipo de determinado de condiciones de existencia y de posición en la estructura social" (Bourdieu, 2008: 19). De esta forma, la Educación
Religiosa como una práctica religiosa se legitima en la medida en que es necesaria para la estructura social; pero, al mismo tiempo, es usada por los obispos como un poder para relativizar a los que están a favor de la apertura religiosa y de legitimarse a ellos mismos como enviados por "mandato divino" a ocupar una posición de privilegio en la estructura social.

El campo religioso donde se mueve la Conferencia Episcopal tiene una ideología específica que se justifica doctrinalmente mediante mitos, ritos y actos litúrgicos. Esta ideología es única en el campo religioso y no permite otra que llegue a mover sus cimientos. Por eso a los obispos les preocupa la apertura de la Educación Religiosa, pues el mundo cultural tradicional fundado y formado desde una visión católica se ve amenazado por el ingreso de otras creencias religiosas. Ante estas circunstancias, los obispos exhortan a los padres de familia para que exijan al Estado la educación católica para sus hijos, pues de no hacerlo se corre el riesgo de que los niños y adolescentes se queden sin Educación Religiosa. Para los prelados, la Educación Religiosa católica seguiría siendo la verdadera, puesto que recoge la cultura tradicional costarricense, en cambio otros credos religiosos se oponen a la cultura cristiana moldeada por la Iglesia Católica. 
Se manifiestan, de esta forma, dos polos opuestos en el campo religioso: uno de ellos lo justifica el poder mismo establecido por un grupo de especialistas, o sea, los obispos; el otro polo es desautorizado por el mismo grupo de especialistas. De igual manera, al exhortar a los padres de familia a exigir Educación Religiosa católica para sus hijos, los obispos manipulan a la colectividad y envían un mensaje subliminal de desaprobación para el MEP. Para ellos, esta institución gubernamental está permitiendo la apertura religiosa y para que eso no se dé los padres de familia deben exigir al Estado el retorno de la Iglesia Católica como rectora de la Educación Religiosa.

Para Bourdieu (2008), el ingreso de otros sistemas religiosos al campo religioso conlleva a un acomodo de éste a nivel ideológico y simbólico. Los especialistas buscan formas que sigan legitimando su poder dentro de dicho campo. Perpetuar el dominio de los medios de producción es básico para seguir justificando su presencia. Por tal razón, los obispos costarricenses, posteriormente al fallo constitucional, hacen un llamado al MEP para que esta institución y la Conferencia Episcopal de Costa Rica sean las dos entidades que consoliden el marco jurídico y funcional del Departamento de Educación Religiosa. En el acomodo del campo religioso desean dejar, por fuera de toda negociación con el MEP, a otros credos. Esto es un principio propio de los grupos de poder, de excluir de una vez por todas a las personas o grupos que se oponen a su pensamiento tradicional. Además, como medio de legitimación, los obispos enfatizan los 70 años en que la Iglesia Católica ha regido los destinos de la Educación Religiosa costarricense. Este intento de legitimación lo hacen por medio de la creación de sentido. La construcción de sentido ha estado asociada con contenidos religiosos que no solo se quedan en el campo natural, sino que trascienden hasta el campo sobrenatural.

La creación de sentido produce un interés implícito, que consiste en mantenerse en el poder de forma vitalicia. Con tal objetivo, los líderes religiosos promueven ideologías que se introducen en la vida cotidiana de la colectividad. Las ideologías cambian en la medida en que se modifican los roles y patrones culturales; pero son ideologías cerradas y conservadoras que buscan legitimar su estructura en la sociedad. Por lo general, toman todos los recursos con los que cuenta una sociedad para justificarse y al mismo tiempo sembrar su posición ideológica (Solera y Robles, 2001). Impregnan toda la cultura, por lo cual se convierten en un elemento cultural, justificado por ella misma. 
En otras palabras, el pensamiento tradicional católico ha estado presente en la sociedad costarricense desde el período de la Conquista y se ha convertido en un elemento de la cultura. Siempre ha estado presente en ella, se ha nutrido de nuevos contenidos y ha cambiado hacia otras formas ideológicas de mayor o menor complejidad de acuerdo con su conveniencia.

Por otra parte, el miedo acompaña a toda persona o grupo de personas y puede producirse de forma colectiva o individual. Existen muchas formas de miedo, algunos suelen suceder de forma inespera$\mathrm{da}$, de coyunturas cotidianas, de argumentos infundados y de carácter patológico, entre otros. Incluso, hay formas de miedo hasta de las cosas de que menos se sospecha. El miedo ha sido usado como un instrumento de poder por diferentes culturas para dominar a otras o por grupos de poder para tener dominadas a las minorías. Según Vega (2010: 54), "el discurso de la ideología del miedo recurre a la imagen de un adversario fuerte y poderoso, al que hay que enfrentar en el mismo terreno". No nos debe extrañar que posteriormente al voto de la Sala Constitucional se infundiera miedo a los profesores y maestros de Educación Religiosa, en el sentido de que iban a perder sus empleos, como resultado de la acción de inconstitucionalidad interpuesta contra la
Missio Canónica. Los demandantes a favor de la apertura de la Educación Religiosa se convirtieron en los adversarios fuertes y poderosos a los que había que enfrentar. Ellos se convirtieron en los responsables de sus desgracias laborales, puesto que la Missio Canónica que les otorgaba la Conferencia Episcopal de Costa Rica había perdido su vigencia; quedaban a merced del MEP. Muchos de los docentes de esta asignatura no contaban con estudios académicos en esta especialidad y habían sido profesores durante varios años amparados a la Missio Canónica; pero, a partir del fallo constitucional sería el MEP quien los nombraría. Además, al no contar ya con la licencia que les confería la Conferencia Episcopal deberían concursar con otras personas posiblemente mejor calificadas que ellas.

El miedo que presentaban los profesores es aprovechado por los obispos para exhortarlos a defender la doctrina católica ante la amenaza de posibles profesores de otros credos religiosos que van a llegar a impartir Educación Religiosa. La apertura de la Educación Religiosa, en vez de verse como una oportunidad para todas las personas que cuentan con los requisitos mínimos para ser docentes de esta asignatura bajo los principios de equidad e igualdad, indiferentemente del credo 
religioso al que pertenezcan, es vista por la Iglesia Católica como una amenaza para la estabilidad laboral de los profesores que son de su bendición, pues este grupo de profesores, en su mayoría laicos, son parte importante de la colectividad que justifica su poder y legitima su presencia en la educación de niños y adolescentes.

El miedo se puede catalogar como una categoría de la violencia simbólica, como también existen otras categorías que se pueden incluir dentro de este tipo de violencia como la creación de sentido, dominación, entre otras. Este tipo de violencia se encuentra en todo el campo religioso, la cual se justifica a sí misma por provenir de los especialistas que ostentan el poder simbólico. En este mismo sentido, para Bourdieu (1997: 172-173):

"Una de las consecuencias de la violencia simbólica consiste en la transfiguración de las relaciones de dominación y de sumisión en relaciones afectivas, en la transformación del poder en carisma o en el encanto adecuado para suscitar una fascinación afectiva (por ejemplo en las relaciones entre jefes $y$ secretarias). El reconocimiento de deuda se convierte en agradecimiento, sentimiento duradero respecto al autor del acto generoso, que puede llegar hasta el afecto, el amor, como resulta particularmente manifiesto en las relaciones entre generaciones.
La violencia simbólica es esa violencia que arranca sumisiones que ni siquiera se perciben como tales apoyándose en unas "expectativas colectivas», en unas creencias socialmente inculcadas. Como la teoría de la magia, la teoría de la violencia simbólica se basa en una teoría de la creencia o, mejor dicho, en una teoría de la producción de la creencia, de la labor de socialización necesaria para producir unos agentes dotados de esquemas de percepción y de valoración que les permitirán percibir las conminaciones inscritas en una situación o en un discurso y obedecerlas."

La violencia simbólica tiene características afectivas y la propia Iglesia Católica la ha utilizado contra los profesores de Educación Religiosa, al persuadirlos para que defiendan la doctrina católica y su posición de agentes pastorales, porque es un envío que les ha dado la Iglesia. Es una deuda que tienen con ella, la cual debe ser cancelada). Esta relación afectiva Iglesiaprofesor es, en el trasfondo, una relación de dominación. La violencia simbólica hace creer al dominado que el dominador es su amigo y defensor, pero lo que se está profundizando en este tipo de relación es la dominación. Los dominados se convierten en codependientes de un sistema y de unas personas que se autodenominan defensores y depositarios de los bienes de salvación. En este mismo sentido, 
Suárez (2006: 22) manifiesta que la religión "juega un rol importante en la creación y sustento de esquemas de percepción, es decir, en la relación entre estructuras de poder y estructuras mentales". Por su parte, Richard (2012: 55) expresa que: "También hoy la Iglesia fracasa cuando usa el poder sagrado para imponerse en la sociedad". En efecto, la religión como estructura de poder contribuye a la imposición de principios de estructuración de percepciones y de pensamiento del mundo social, pero también pierde terreno ante una sociedad cada vez más crítica y exigente.

De hecho, el campo religioso es una construcción científica que se usa para explicar los diversos fenómenos que ocurren en el ámbito religioso. Es un sistema con un conjunto de creencias y con grupos de especialistas dotados de un conocimiento que solo ellos son capaces de explicar. El campo religioso vende e intercambia bienes simbólicos de salvación. Comparte formas de poder (poder político, poder económico, poder religioso). Apela a las masas humanas (colectividades), donando identificaciones ideológicas y forjando identidades (identidad política/ identidad religiosa), sin que ellas sean necesariamente opuestas. Pretenden fines trascendentes como la salvación personal y colectiva, el reino de Dios, entre otros, y metas inmanentes como el bienestar social, cultural, económico, estado de derecho (la justicia y la paz). Estas metas se hallan ligadas a los intereses mediáticos que persiguen los especialistas del campo religioso y son interpretadas desde su posición de privilegio. Los obispos costarricenses -como especialistas del campo religioso- delimitan cuáles fines trascendentes son más importantes para su campo religioso de acuerdo con la coyuntura que están atravesando. Por eso, en unos momentos enfatizan más en un fin que en otro o viceversa. Este dualismo se puede percibir antes y después del voto de la Sala IV. Así mismo, las metas inmanentes son definidas desde el espacio de los especialistas y ellos deciden qué se entiende y qué se debe hacer en relación con cada una de estas metas. Los obispos interpretaron las metas desde sus intereses mediáticos, por lo cual difícilmente iban a coincidir con los intereses de los promotores de la acción de inconstitucionalidad, pues la interpretación y los resultados que ambos grupos les dieron eran muchas veces contradictorios.

Finalmente, es necesario señalar que el campo religioso posee características moralizantes. Los principios morales le dan sustento a su estructura religiosa. Los especialistas a través de la moral educan a la colectividad y determinan lo que es moral e inmoral. Como los 
especialistas del campo religioso, los obispos tienen un perfil establecido de cómo debe ser en lo moral un docente de Educación Religiosa. Prácticamente, quien cumple con los preceptos de la Iglesia y recibe los sacramentos se puede considerar que está dentro de la escala moral del campo religioso; pero los educadores que contraen matrimonio civil, o se encuentran en unión de hecho o libre, madres solteras y profesores que se cambian a otro credo religioso son considerados inmorales por los propios obispos. Aunque después del voto de la Sala IV todas las personas consideradas inmorales por la Iglesia Católica pueden impartir lecciones de Educación Religiosa sin ser despedidas, para los obispos este tipo de personas sigue siendo inmoral de acuerdo con su visión de mundo. Estas personas están excluidas de los bienes de salvación de por vida si no corrigen su inmoralidad. La moral se usa en el campo religioso para poner límites y orden, y exige a sus seguidores una forma de vivir y unos principios por seguir.

\section{Conclusión}

El voto de la Sala Constitucional vino a democratizar la Educación Religiosa, en el sentido de que les abrió las puertas de la oportunidad a todas las personas que querían ser docentes de Educación
Religiosa, sin importar raza, denominación religiosa, sexo y color, entre otras. Lo único necesario es tener los requisitos que el MEP solicita, a saber: estudios académicos e idoneidad. De este modo, los principios de equidad e igualdad se comenzaron a aplicar a principios de 2011, cuando el Servicio Civil y el MEP organizaron el primer reclutamiento para profesores de Educación Religiosa con el fin de optar a puestos interinos y en propiedad. Varios meses después, el MEP informó de los resultados. Cabe destacar que varias personas consideradas "inmorales" por la Conferencia Episcopal antes del fallo constitucional lograron obtener propiedad, otras se colocaron en puestos interinos.

El fallo de la Sala IV establece que el MEP en un futuro cercano tiene que diseñar los programas de Educación Religiosa con una visión ecléctica. Esto quiere decir que debe ser una educación abierta donde se contemplen las diferentes religiones presentes en nuestra realidad nacional. De este modo, la religión debe ser fiel a su función y no puede ser un cuerpo extraño en el complejo cultural en donde vive, $\sin$ que esto signifique que ella deba renunciar a su tarea profética.

En la medida en que lo ecléctico o lo ecuménico vaya introduciéndose en los programas de Educación Religiosa de primaria y 
secundaria, la visión unidireccional a una interpretación doctrinal y a una Teología homogénea -como se ha venido haciendo normalmente durante muchos años- comenzará a ceder terreno ante una visión pluralista de diálogo interreligioso y de interculturalidad entre los diferentes grupos que coexisten en el país. Se espera que esta renovación curricular se produzca con respeto y que sea beneficiosa para el desarrollo del país.

Es necesario enfatizar que la transición de la Educación Religiosa hacia un campo religioso más abierto requiere una sociedad democrática y pluralista, en la cual el reconocimiento de la diversidad se explicite claramente en una apertura que no solo posibilite la convivencia, sino que avance hacia la interrelación facilitando la comprensión, el respeto y el diálogo.

Por lo tanto, la Educación Religiosa se encuentra en renovación en los ámbitos administrativo y académico por parte del MEP. Nuevos profesores con una visión más ecléctica se están incorporando al cuerpo docente de escuelas y colegios. Hay más equidad e igualdad a la hora de reclutarse, porque los requisitos solicitados por parte del Servicio Civil y el MEP son los mismos para todos. Si estos cambios siguen dando frutos, se espera en los próximos años una Educación
Religiosa completamente renovada $\mathrm{y}$ fortalecida.

\section{Bibliografía}

Bourdieu, P. (1997). Razones prácticas sobre la teoría de la acción. Barcelona: Anagrama.

Bourdieu, P. (2008). Génesis y estructura del campo religioso. Recuperado de http://davidvelasco.files.wordpress. com/2008/01/genesis-y-estructura-delcampo-religioso.pdf

Comité de Derechos Humanos de la Organización de las Naciones Unidas (1994). Observaciones finales del Comité de Derechos Humanos. Recuperado de http://www1.umn.edu/humanrts/hrcommittee/spanish/costarica1994.html

Conferencia Episcopal de Costa Rica (13 de setiembre de 1990). Artículo 90 del acta de la sesión $\mathrm{N}^{\mathrm{o}} 10-90$ de la Conferencia Episcopal de Costa Rica. San José: Archivo de la Conferencia Episcopal de Costa Rica.

Conferencia Episcopal de Costa Rica (agosto de 2010). Boletín 15, 72-74. Recuperado de http://www.iglesiacr.org/2012/ files/CECOR15.pdf

Hess, C. (2010). Educación religiosa integral $y$ de calidad. Recuperado de http:// hess-cr.blogspot.com/2010/04/educacion-religiosa-integral-y-de.html

Richard, P. (2012). Orígenes del cristianismo: Memoria para una reforma de la Iglesia. Revista Espiga. XI (23): 53-77.

Sala Constitucional de la Corte Suprema de Justicia (24 de agosto de 2011). Acción de Inconstitucionalidad. Expediente 
08-010483-0007-CO, voto 2023-2010.

Boletín Judicial 162, 27- 45. Recuperado de http://www.boletinjudicial.go.cr/ pub/2011/08/bol_24_08_2011.pdf

Solera M., E.; Robles R., J. A. (2001). Religión, sociedad, crisis. San José: FLACSO.
Suárez, H. J. (2006). Pierre Bourdieu y la Religión: una introducción necesaria. Revista Relaciones. XXVII (108): 19-27.

Vega S., Á. (2010). El despertar de la ciudadanía: ideología del miedo y cultura de la no violencia en Costa Rica. Heredia: EUNA. 
